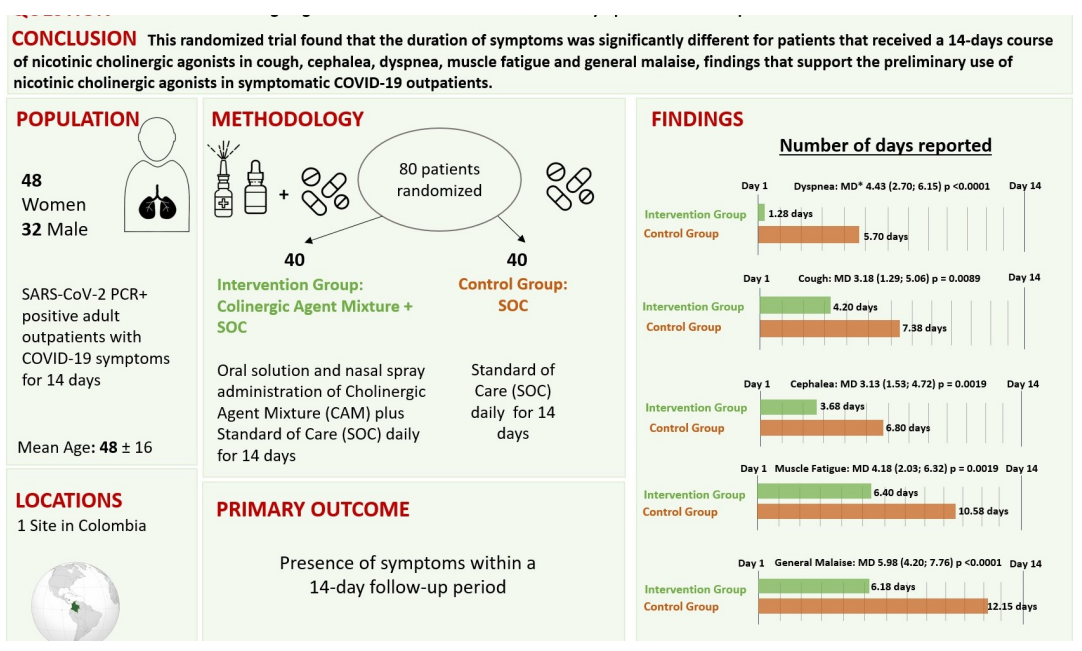

\title{
EFFECTIVENESS IN HUMANS OF
}

orlando Angulo ${ }^{1}$, Hector Fabio Restrepo ${ }^{2}$, José Gabriel León Higuera, Mario Leon Garcia, Fernando Mendive $^{3}$, matteo politi ${ }^{4}$

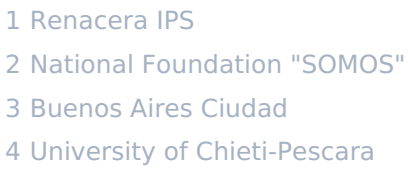

Funding: The author(s) received no specific funding for this work.

Potential competing interests: The author(s) declared that no potential competing interests exist.

\section{Abstract}

\section{Background:}

Since the SARS-CoV-2 pandemic emerged in December 2019, it has triggered 4.4 million deaths and strained health systems across the world. Yet more than a year and a half since the pandemic emerged, therapeutic drugs to treat COVID-19 disease are limited.

\section{Objective}

To investigate the therapeutic potential of a nicotinic Cholinergic Agonists Mixture (CAM), delivered daily as oral drops and as nasal spray, in alleviating ten common COVID-19 related symptoms in 80 symptomatic human adults with confirmed SARS-CoV-2.

\section{Methods}

This randomized open-label pilot trial recruited 80 symptomatic adults with confirmed SARS-CoV-2 infection after RT-PCR + test less than five days. Participants were recruited from databases of several Colombian hospitals and were randomly assigned to the control group, which received the Standard of Care (SOC) treatment (outpatient treatment), or the intervention group, which received SOC combined 
with the Cholinergic Agent Mixture (CAM + SOC). Both groups received their treatment for a total of 14 days. The duration of symptoms was compared across the 14-day period.

\section{Results:}

This study found statistically significant reductions in symptom duration for 5 out of 10 symptoms, including dyspnea (reduction of 4.43 days [95\% Cl: $2.70 ; 6.15$ ], p < 0.0001 ), cough (reduction of 3.18 days [95\% Cl: $1.29 ; 5.06$ ], $p=0.0089$ ), cephalea (reduction of 3.13 days [95\% $\mathrm{Cl}: 1.53 ; 4.72$ ], $p=$ 0.0019 ), muscle fatigue (reduction of 4.18 days [95\% Cl: $2.03 ; 6.32$ ], $p=0.0019$ ) and general malaise (reduction of 5.98 days [95\% Cl: $4.20 ; 7.76], p<0.0001$ ). The study found no significant reductions in the duration of the following symptoms: fever, ageusia, anosmia, chest tightness, and nasal congestion.

\section{Conclusion:}

In comparison to the control group, the intervention group witnessed statistically significant and clinically relevant reductions in the duration of 5 out of 10 common COVID-19 disease symptoms within two weeks.

This includes a reduction of approximately 4.4 days in the duration of dyspnea, a symptom that appears to be strongly correlated to severe COVID-19 disease and admission to Intensive Care Units.

Further studies are needed to confirm these preliminary findings and to evaluate whether this specific nicotinic cholinergic agonists mixture could have implications for public health.

\section{CHOLINERGIC AGONISTS AGAINST COVID-19 IN HUMANS. RESULTS FROM A RANDOMIZED OPEN LABEL}

\section{PILOT TRIAL}

León Higuera J.G. ${ }^{1,2}$, Restrepo Guerrero F.H, 6 , León García M. ${ }^{7}$, Politi M ${ }^{8}$, Mendive F. ${ }^{9}$, Angulo O.J. ${ }^{3,4^{*}}$ 1 Sports and medicine department at the San José Children's University Hospital and at the San José University Hospital in Bogotá, Colombia

2 Assistant professor of the physical activity and sports medicine residency at the Health Sciences University Foundation, Colombia 3 Professor and Researcher at Universidad Cooperativa de Colombia, Villavicencio, Colombia

4 Sports Medicine Physician, Certificate Diploma in Sports Nutrition, Master in HIV-AIDS. HIV-AIDS. Sports Medicine, Sports Nutrition and HIV-AIDS Department, Renacerá IPS Villavicencio, Colombia

5 Physician, Veterinarian, Epidemiologist, Assistant Professor Research Division at University Foundation of Health Sciences,

Colombia

6 Research Director at National Foundation "SOMOS", Colombia

7 Physician, specialized in Pneumology by the by the Health Sciences University Foundation, Colombia, member of the Colombian Pneumological Foundation.

8 PhD in Chemistry and Technology of Bioactive Substances, Department of Pharmacy, University of Chieti-Pescara, Chieti Scalo, Italy

9 Biochemist. PhD in Molecular Biology, Doctor of the University of Buenos Aires, Specialist in Molecular Biology, Department of Genetics and Molecular Biology, College of Pharmacy and Biochemistry, Argentina

* Corresponding author 


\section{GRAPHICAL ABSTRACT}

\section{HIGHLIGHTS:}

- This study is the first randomized trial evaluating the real-life impact of specifically formulated nicotinic cholinergic agents as adjuvant therapy in the treatment of out care symptomatic adult patients with confirmed COVID-19.

- This randomized open-label study revealed that a unique mixture of nicotinic cholinergic agonists significantly reduced the duration of common COVID-19 symptoms, including dyspnea, cough, cephalea, general malaise and muscle fatigue.

- Dyspnea appears to be associated with severe COVID-19, hospitalization, and death, being a relevant significative predictor symptom for ICU admission.

- These preliminary findings indicate that the specific mixture of nicotinic cholinergic agonists could reduce COVID-19 disease severity, with implications for public health.

\section{ABSTRACT}

Background:

Since the SARS-CoV-2 pandemic emerged in December 2019, it has triggered 4.4 million deaths and strained health systems across the world. Yet more than a year and a half since the pandemic emerged, therapeutic drugs to treat COVID-19 disease are limited.

\section{Objective}

To investigate the therapeutic potential of a nicotinic Cholinergic Agonists Mixture (CAM), delivered daily as oral drops and as nasal spray, in alleviating ten common COVID-19 related symptoms in 80 symptomatic human adults with confirmed SARS-CoV-2.

\section{Methods}

This randomized open-label pilot trial recruited 80 symptomatic adults with confirmed SARS-CoV-2 infection after RT-PCR + test less than five days. Participants were recruited from databases of several Colombian hospitals and were randomly assigned to the control group, which received the Standard of Care (SOC) treatment (outpatient treatment), or the intervention group, which received SOC combined with the Cholinergic Agent Mixture (CAM + SOC). Both groups received their treatment for a total of 14 days. The duration of symptoms was compared across the 14-day period.

Results:

This study found statistically significant reductions in symptom duration for 5 out of 10 symptoms, 
including dyspnea (reduction of 4.43 days [95\% Cl: $2.70 ; 6.15$ ], $\mathrm{p}<0.0001$ ), cough (reduction of 3.18 days [95\% Cl: $1.29 ; 5.06$ ], $p=0.0089$ ), cephalea (reduction of 3.13 days [95\% Cl: $1.53 ; 4.72$ ], $p=0.0019$ ), muscle fatigue (reduction of 4.18 days [ $95 \% \mathrm{Cl}: 2.03 ; 6.32$ ], $p=0.0019$ ) and general malaise (reduction of 5.98 days $[95 \% \mathrm{Cl}: 4.20 ; 7.76], p<0.0001)$. The study found no significant reductions in the duration of the following symptoms: fever, ageusia, anosmia, chest tightness, and nasal congestion.

\section{Conclusion:}

In comparison to the control group, the intervention group witnessed statistically significant and clinically relevant reductions in the duration of 5 out of 10 common COVID-19 disease symptoms within two weeks. This includes a reduction of approximately 4.4 days in the duration of dyspnea, a symptom that appears to be strongly correlated to severe COVID-19 disease and admission to Intensive Care Units.

Further studies are needed to confirm these preliminary findings and to evaluate whether this specific nicotinic cholinergic agonists mixture could have implications for public health.

\section{ABBREVIATIONS}

ACE2, angiotensin-converting enzyme II; CAM, Cholinergic Agent Mixture; CNS, Central Nervous System; ICU, Intensive Care Unit; I+SOCG, intervention group; mMRC, modified Medical Research Council scale; NRT, Nicotine Replacement Therapy; nAChRs, nicotinic acetylcholine receptors; RBD, receptor-binding domain; ROF, rating-of-fatigue; SOC, Standard of Care treatment; SOCG, control group; TBS, toxin-binding site; VAS, Visual Analogue Scale

\section{KEYWORDS}

Cholinergic agonists; Cholinergic system; COVID-19; Nicotine; Nicotinic acetylcholine receptors; nAChR; SARS-CoV-2; nAChR; Human trial; Anti-inflammatory cholinergic pathway, Long Covid, Post-Covid Syndrome

\section{INTRODUCTION}

Several lines of evidence have suggested that nicotinic cholinergic agonists could protect against COVID19 disease. Clinical evidence including peer-reviewed studies found a lower prevalence of COVID-19 among smokers, which it could be attributed to a probable protective factor for nicotine contained in the cigarettes but not from cigarette or smoking itself (1-5). A nicotinic hypothesis on SARS-COV-2 $(1,6)$ and on the probable effectiveness of cholinergic agonists in COVID-19 disease has been proposed $(2,7)$ according to clinical observations and peer-reviewed studies $(4,8-11)$. This controversial nicotinic hypothesis $(4,12)$ is currently under debate. A highly conserved cryptic epitope in the S1-SARS-CoV-2 (aa 365-390) that is involved in the disruption of $\alpha 7$-nAChR has been described (13-15) involving an interaction between SARSCoV-2 glycoprotein S and a extracellular domain of the alpha9 and alpha7 subunit of nAChR, forming a "toxin binding site" region with the nAChRs (16). The Spike protein of SARS-CoV2 has sequences homologous to snake venom neurotoxins with nicotinic acetylcholine receptor antagonist activity $(1,17)$. This activity is thought to be involved in paralysis and autonomic nervous system dysfunctions including the anti-inflammatory cholinergic pathway of the vagus nerve regulating 
macrophage activity (18). Recent computational modulations showed an interaction between SARS-CoV-2 and $\mathrm{nAChR}$ and the disruption in the anti-inflammatory response of the cholinergic system (19). This interaction between the alpha 7 subunits and the SARS-CoV-2 glycoprotein S1 was disrupted when cholinergic agonists and molecules such as acetylcholine, carbamylcholine, cytisine, epibatidine, galantamine, nicotine, succinylcholine and varenicline were docked.

However, the present study was based on a novel synergistic combination of nicotine with cotinine, anatabine, anabasine, as well as s-allyl-cysteine and 6-gingerol in lower proportions, which has not previously been suggested.

COVID-19 disease has been associated with inflammatory changes in the brain and the choroid plexus (20) as well with several cognitive disorders even after viral clearance and regardless of disease severity including anxiety, depression (21), memory loss, attention and executive function deficit (22), being psychiatric disorders such as schizophrenia, where $\alpha 7$-nicotinic acetylcholine receptor deficiency plays an important role (23), an associated risk-factor for worse or fatal outcome in COVID-19 (24). Cholinergic agonist molecules such as nicotine used therapeutically are safe and well tolerated $(25,26)$ and even at long-term use (27). Nicotine does not have relevant or minimal side effects and has been approved by FDA (28) and several other drug regulation authorities in the context of smoking cessation. Nicotine nasal spray it is used and has been studied among pregnant women as Nicotine Replacement Therapy (NRT) (29). This applies also for non-smokers, concomitant smokers or to smokers with cardiac disease (26,30-38). Nicotine itself as a molecule, aside from the cigarette, does not exhibit carcinogenic properties (39) and its medicinally inhaled nasal application does not significantly alter lung function, nor diastolic blood pressure when compared with placebo (40). Cotinine is a non-addictive and safe molecule (41) with pharmacokinetic properties suitable for therapeutic use with anxiolytic, antidepressant, antipsychotic and anti-neuroinflammatory properties (42). Cotinine behaves as a nAChR positive allosteric modulator and its neurobehavioral effects significantly differ from those from nicotine alone (43). Anabasine has a higher and more specific agonist effect on the nicotinic $\alpha 7-n A C h R$ subtype than other nicotinic agonist molecules and has been noticed to ameliorate memory and cognitive deficits (23) attenuating also nicotine withdrawal (44) like in the case of anatabine (45). Anatabine has a powerful antiinflammatory effect and prevents IL-1b production, reducing pro-inflammatory cytokine production such as IL-6, IL-1b and TNF- $\alpha$ in the plasma (46), biomarkers that are associated predictors for severity and death in COVID-19 (47). 6-gingerol has been found to have various pharmacological effects including antiinflammatory, analgesic, antipyretic, angiogenic, antioxidant $(48,49)$, and neuroprotective properties $(50)$. In animal models it also facilitates healthy glucose regulation for diabetes $(51,52)$, a comorbidity associated to a higher risk and a more severe outcome for COVID-19 (53). S-allyl-cysteine has antioxidative, cardiovascular and neuronal degeneration protection properties (54-56) and has been proposed as a candidate for inhibiting SARS-CoV-2 (57).

The present randomized open-label trial pilot study in humans has been carried out with a new drug that has recently been specifically designed against COVID-19 by the company Niccovid and has been 
preliminarily named Cholinergic Agent Mixture (CAM). The administration of the novel combination of ingredients in CAM under pulverized intranasal aerosol or nasal spray has been specifically designed to achieve an excitatory and therapeutic effect much faster and more directly on arrival at the CNS than other routes such as sublingual or transdermal (58-61). Indeed, the nasal spray has the advantage of offering better and efficient absorption (62), and a higher excitatory effect of cholinergic agonist molecules than patches or tablets. Thus, the therapeutic strategy of CAM use is to provide a slower sustained systemic effect by the oral route with the administration of oral drops in combination with a rapid neurotropic and excitatory effect by nasal spray administration, adapting dosage according to the patient's profile and needs.

\section{METHODS}

\subsection{Study design}

This randomized-open trial was conducted in the city of Bogotá in Colombia, in 80 adult patients that tested positive for SARS-CoV-2 through PCR-RT test. Patients were recruited from several official databases of Colombian hospitals and randomized through sequential and consecutive assignment following their status as a symptomatic SARS-CoV-2 positive patients in the last 5 days. To reduce bias, the health care professionals who monitored the patients' symptoms were blinded to the group that was assigned to the patient or to the medicine they were giving.

The intervention group (I+SOCG) consisted of 40 infected patients. Following a positive COVID-19 RT-PCR test within 5 days, patients received Standard of Care (SOC) plus a daily dose of CAM nasal spray (0.128 $\mathrm{mL}$, on each nostril) every twelve hours and CAM oral drops $(0.560 \mathrm{~mL}$, in $175 \mathrm{~mL}$ of water every 3 times per day).

The control group (SOCG) consisted of 40 infected patients and was administered with only SOC following a positive SARS-CoV-2 RT-PCR test within 5 days.

SOC was prescribed in both groups by physicians as a part of their standard treatment to mitigate COVID19 symptoms (see table 1 for SOC medications).

Both groups were monitored on a daily basis to assess the evolution of symptomatic COVID-19 disease, based on a range of scales: binary scales for absence or presence for cephalea, cough, ageusia, anosmia, chest tightness and nasal congestion; mMRC scale for dyspnea (63), updated Gunnar Borg's for muscular fatigue $(64,65)$, and Visual Analogue Scale (VAS) for general malaise, an analogue scale to sick building syndrome (66) and to rating-of-fatigue (ROF) (67).

\section{Inclusion criteria:}

- RT-PCR positive for SARS-CoV-2 within five days.

- Outpatient under ambulatory care (non-hospitalized)

- Symptomatic patient

\section{Exclusion criteria:}

- Patient under in-ward hospital care, even if they have positive antigens and / or RT-PCR+ test.

- Decline in study participation. 
- Asymptomatic patient even if having a RT-PCR+ test for SARS-CoV-2.

- Under 18 years old.

\subsection{Participants}

The study population consisted of 80 adult Colombian patients (48 women and 32 men) who attended various official hospital services in Colombia and were diagnosed with SARS-CoV-2 infection confirmed by real-time reverse transcription polymerase chain reaction (RT-PCR) testing performed on nasopharyngeal swab specimens (See Fig 1).

\section{Fig 1.}

Study flow diagram: Intervention Group (I+SOCG): with Cholinergic Agent Mixture (CAM) and Standard of Care (SOC). Control Group (SOCG): control group with only Standard of Care (SOC). (See table 1 for detail).

\subsection{Intervention}

The CAM treatment, consisting of combined administration of oral drops and nasal spray on a daily basis to the intervention group, is mainly composed of cholinergic nicotinic agonist agents, although some noncholinergic agonists agents with known antiviral activity with synergistic interactions were also added in the CAM composition. The technical dossier of the composition with its formulation and safety profile was submitted to the Colombian food and drug administration (INVIMA) and its application was accepted. The application is currently in the process of approval for definitive health registration.

The Standard of Care $(\mathrm{SOC})$ administered to both groups was prescribed by the treating physicians prior to the study and included various drugs such as antipyretics, NSAIDs, ivermectin, among others (see Table 1).

\subsection{Demographics, comorbidities, medications, and endpoints}

The following demographic and clinical data were collected: gender, age, date of suspected infection, date of RT-PCR+ for SARS-CoV-2, smoking status, previous comorbidities, SOC's prescribed drugs for COVID-19 symptoms. Following COVID-19 related symptoms were daily measured as endpoints in both groups: fever, cough, dyspnea, muscle fatigue, cephalea, ageusia, anosmia, chest pressure, general malaise, and nasal congestion.

The following comorbidities present prior to SARS-CoV-2 infection such as cardiovascular disease, hypertension, hypothyroidism, obesity, among others, were also documented in two groups (See table 1). Following medications prescribed as SOC such as salbutamol, NSAIDs, antihistamines and others were reported in both groups (See table 1). Medications prescribed previously to SARS-CoV-2 infection for ongoing comorbidities were also collected in both groups such as NSAIDs, corticosteroids, antipyretics, among others (See Table 2).

In the intervention group (I+SOCG) discomfort manifestations after CAM's oral drops intake and CAM's nasal spray administration were also reported to assess tolerance and possible side-effects of CAM (see 
Table 3).

The evaluation in both groups, where the interventional group (I+SOCG) was administered with CAM + SOC and the control group (SOCG) was administered with only SOC, was carried out for 14 days assessing the improvement or worsening of each symptom on a daily basis. At day 0 an initial measurement of symptoms without the administration of CAM in the intervention group (I+SOCG) and in the control group (SOCG) was performed where both groups were already under SOC treatment. In days 1 to 14 the measurement of the evolution of each symptom with SOC + CAM for group I+SOCG and without CAM but with SOC for group SOCG was also equally assessed.

The following symptoms were measured binarily (yes/no) for absence or presence of the symptom: fever $\left(\geq 38^{\circ}\right)$, cephalea, cough, ageusia, anosmia, chest tightness and nasal congestion. Dyspnea was calculated from 0 to 4 according to the modified mMRC (Medical Research Council) scale, which is useful in dyspnea evaluation in physical activities of daily living (63) and in COVID-19 $(68,69)$. Muscular fatigue was calculated from 0 to 10 according to Gunnar Borg's updated scale devised in the 1980s and improved a few years ago, a system for assessing intensity based not on value measurements but on the patient's own perception of effort $(64,65)$.

General malaise for measuring its intensity was calculated from 0 to 10, a commonly usual assessment method similar to Visual Analogue Scale (VAS) in sick building syndrome (66) and to rating-of-fatigue (ROF) (67).

To proceed with the analysis, the dichotomization of symptoms in the non-binary scales was categorized as follows: dyspnea (mMRC score $\leq 1$ versus mMRC score $\geq 2$ ) (70-72); muscle fatigue (absence -0- versus presence -1 to 10-) (67,73); general malaise (absence -0- versus presence -1 to 10-).

The raw data were compiled in a table using Microsoft Excel by trained health professionals.

\subsection{Statistical Analysis}

Qualitative variables are reported as absolute frequencies and percentages while quantitative variables are reported as means and standard deviations. In order to compare the expected value of quantitative variables in the I+SOCG vs the SOCG the t-test (assuming heterogenous variances) was used, whereas for qualitative variables the chi-square test for independence was used. Although most quantitative variables cannot be considered as normal (outcomes of interest like number of days with a given symptom), the ttest was still used in place of non-parametric alternatives, since t-test is highly robust in non-normality conditions (74).

Effect measures were used to quantify the differences between the two groups using the mean difference (estimated assuming heterogenous variances) and odds ratios with their corresponding 95\% confidence intervals.

In this study multiple symptoms were assessed as outcomes of interest and baseline demographics, comorbidities and Standard of Care (SOC) treatments for COVID-19 were also evaluated in order to 
determine the comparability between intervention and control groups. Thus, multiple comparison adjustment was done using the false discovery rate approach proposed by Benjamini et al. (75), setting a global significance level of $5 \%$.

All statistical analyses were done in software R version 4.2.0 (76).

\subsection{Ethics committee approval}

This study was verified and evaluated by the Cediff Biomedical Research Ethics Committee, stating that the protocol complies with the ethical standards described in the national and international regulations related to biomedical research. The risk-benefit ratio was found favorable by the Ethics Committee for the participants enrolled in the research, which is widely described in the justification of the study protocol and informed consent.

\section{RESULTS}

Both groups had the same number of patients $(n=40)$ and were analogous in terms of age (I+SOCG: $45.2 \pm$ 18.0 years; SOCG: $50.5 \pm 13.1$ years) and gender (I+SOCG: $47 \%$ male; SOCG: $32.5 \%$ male). The ethnicity all participants was white ( $88 \%$ of Colombian population is white) and their smoking status was also assessed, $0 \%$ of the participants were current smokers nor former recent smokers in either group. In comparative terms, any of the prior referred comorbidities did not differ significantly (see Table 1) in both groups, being hypertension (27.5\% in the intervention group and $37.5 \%$ in the control group) and chronic obstructive pulmonary disease ( $12.5 \%$ in the intervention group and $25 \%$ in the control group) the most common ones, except for cardiovascular disease which was present in the interventional group (25\%) and absent in the control group $(p=0.0121)$. Of the 14 medications prescribed as SOC in both groups for COVID-19 symptoms mitigation no significant differences were observed in both groups in the prescribed drugs except for antipyretics that were more present in the control group ( $p=0.0013$ ), (See table 1 ). Also, no significant differences were found in any of the medications prescribed for comorbidities prior to COVID19 in both groups (See Table 2 ) being angiotensin-converting enzyme inhibitors $(15.0 \%$ in the intervention group and $12.5 \%$ in the control group) and angiotensin II receptor blockers (5.0\% in the intervention group and $10.0 \%$ in the control group) the most common used medications.

When evaluating in days the presence of COVID-19 associated symptoms at the final day of the study (day 14) a statistically significant reduction of symptoms after adjusting $p$ - values in the intervention group was observed in dyspnea (reduction of 4.43 days [95\% Cl: $2.70 ; 6.15], p<0.0001$ ), cough (reduction of 3.18 days [95\% Cl: $1.29 ; 5.06$ ], $p=0.0089$ ), cephalea (reduction of 3.13 days [95\% $\mathrm{Cl}: 1.53 ; 4.72$ ], $p=0.0019$ ), muscle fatigue (reduction of 4.18 days [ $95 \% \mathrm{Cl}: 2.03 ; 6.32$ ], $p=0.0019$ ) and general malaise (reduction of 5.98 days [95\% Cl: $4.20 ; 7.76], \quad p<0.0001$ ) (See table 1 and Fig 2). No significant differences were found in the remaining symptoms (see Table 1 ).

No adverse effects were reported in the application of oral drops of the Cholinergic Agent Mixture (CAM) in the intervention group that took CAM. The nasal spray administration of the CAM produced mild transient 
effects such as nasal or oropharyngeal itching, among others, which lasted an average of 7 minutes (SD 4) and no major complications were observed (see table 3).

Fig. 2.

Boxplots for symptoms with significant $p$-value representing the presence of each symptom in number of days for each group (intervention group = I+SOCG; control group = SOCG) during the 14 days of the evaluation.

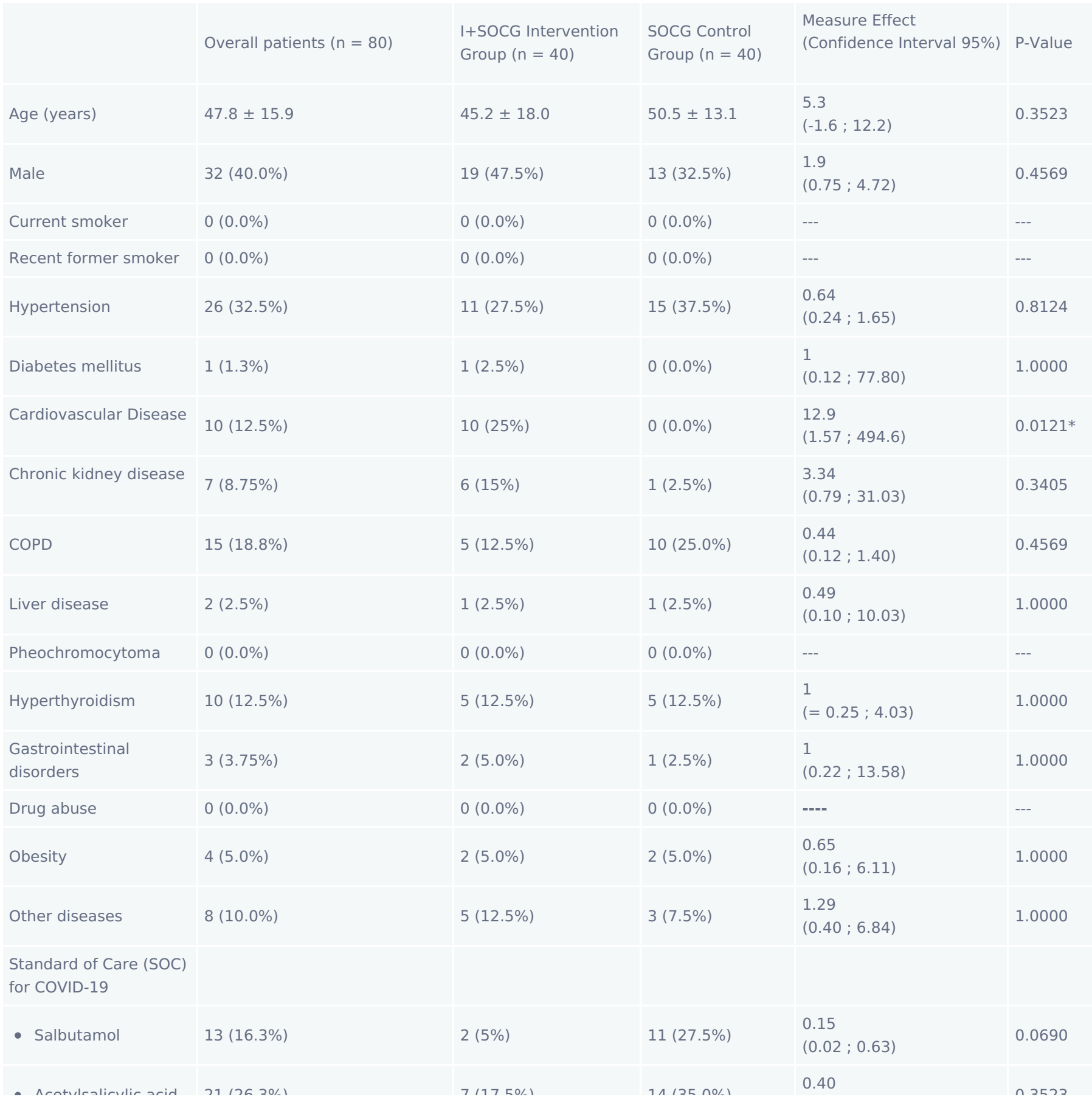




\begin{tabular}{|c|c|c|c|c|c|}
\hline 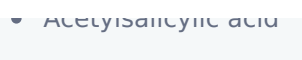 & $\angle+\mid<$ U.J & (1+1, & (4) & $(0.13 ; 1.13)$ & ט.נJ\& \\
\hline - NSAIDs & $16(20.0 \%)$ & $11(27.5 .0 \%)$ & $5(12.5 \%)$ & $\begin{array}{l}2,59 \\
(0.83 ; 9.25)\end{array}$ & 0.3559 \\
\hline - Azithromycin & $10(12.5 \%)$ & $4(10.0 \%)$ & $6(15.0 \%)$ & $\begin{array}{l}0.64 \\
(0.15 ; 2.51)\end{array}$ & 1.0000 \\
\hline - Nebulizers & $3(3.8 \%)$ & $1(2.5 \%)$ & $2(5.0 \%)$ & $\begin{array}{l}0.32 \\
(0.07 ; 4.65)\end{array}$ & 1.0000 \\
\hline - Ivermectin & $11(13.8 \%)$ & $7(17.5 \%)$ & $4(10.0 \%)$ & $\begin{array}{l}1.87 \\
(0.50 ; 7.99)\end{array}$ & 0.8446 \\
\hline - Enoxaparin & $1(1.3 \%)$ & $1(2.5 \%)$ & $0(0.0 \%)$ & $\begin{array}{l}1 \\
(0.12 ; 77.80)\end{array}$ & 1.0000 \\
\hline $\begin{array}{l}\text { - Unfractionated } \\
\text { heparin }\end{array}$ & $0(0.0 \%)$ & $0(0.0 \%)$ & $0(0.0 \%)$ & --- & --- \\
\hline - Hydroxychloroquine & $0(0.0 \%)$ & $0(0.0 \%)$ & $0(0.0 \%)$ & --- & --- \\
\hline - Glucocorticoids & $8(10.0 \%)$ & $4(10.0 \%)$ & $4(10.0 \%)$ & $\begin{array}{l}0.78 \\
(0.25 ; 3.99)\end{array}$ & 1.0000 \\
\hline - Oxygen therapy & $2(2.5 \%)$ & $1(2.5 \%)$ & $1(2.5 \%)$ & $\begin{array}{l}0.49 \\
(0.10 / 10.03)\end{array}$ & 1.0000 \\
\hline - Antihistamine & $5(6.3 \%)$ & $5(12.5 \%)$ & $0(0.0 \%)$ & $\begin{array}{l}5.56 \\
(0.67 ; 235)\end{array}$ & 0.2328 \\
\hline - Anti-influenza drugs & $9(11.3 \%)$ & $8(20.0 \%)$ & $1(2.5 \%)$ & $\begin{array}{l}4.73 \\
(1.14 ; 41.53)\end{array}$ & 0.1350 \\
\hline - Antipyretics & $32(40.0 \%)$ & 7 (17.5\%) & 25 (62.5\%) & $\begin{array}{l}0.13 \\
(0.04 ; 0.36)\end{array}$ & $0.0013^{*}$ \\
\hline - Antibiotics & $4(5.0 \%)$ & $1(2.5 \%)$ & $3(7.5 \%)$ & $\begin{array}{l}0,23 \\
(0.06 ; 2.90)\end{array}$ & 0.9516 \\
\hline $\begin{array}{l}\text { - Vitamin } \\
\text { supplements }\end{array}$ & $1(1.25 \%)$ & $1(2.5 \%)$ & $0(0.0 \%)$ & $\begin{array}{l}1 \\
(0.12 ; 77.80)\end{array}$ & 1.0000 \\
\hline $\begin{array}{l}\text { COVID-19 related } \\
\text { symptoms }\end{array}$ & $\begin{array}{l}\text { Overall patients }(n=80) \text {. } \\
\text { Number of days reported }\end{array}$ & $\begin{array}{l}\text { I+SOCG Intervention } \\
\text { Group }(n=40) \\
\text { Number of days } \\
\text { reported }\end{array}$ & $\begin{array}{l}\text { SOCG Control } \\
\text { Group }(n=40) \\
\text { Number of days } \\
\text { reported }\end{array}$ & $\begin{array}{l}\text { Measure Effect } \\
\text { (Confidence Interval 95\%) }\end{array}$ & P-Value \\
\hline Fever & $1.8 \pm 3.2$ & $1.15( \pm 2.31)$ & $2.43( \pm 3.18)$ & $\begin{array}{l}1.28 \\
(-0.11 ; 2.66)\end{array}$ & 0.2443 \\
\hline Cough & $5.8 \pm 4.6$ & $4.20( \pm 4.33)$ & $7.38( \pm 4.29)$ & $\begin{array}{l}3.18 \\
(1.29 ; 5.06)\end{array}$ & $0.0089 *$ \\
\hline Cephalea & $5.2 \pm 3.9$ & $3.68( \pm 3.08)$ & $6.80( \pm 4.12)$ & $\begin{array}{l}3.13 \\
(1.53 ; 4.72)\end{array}$ & 0.0019* \\
\hline Ageusia & $3.7 \pm 5.1$ & $3.03( \pm 4.38)$ & $4.38( \pm 5.74)$ & $\begin{array}{l}1.35 \\
(0.89 ; 3.59)\end{array}$ & 0.4569 \\
\hline Anosmia & $2.6 \pm 3.9$ & $2.50( \pm 3.91)$ & $2.63( \pm 3.95)$ & $\begin{array}{l}0.13 \\
(-1.59 ; 1.85)\end{array}$ & 1.0000 \\
\hline Chest tightness & $2.9 \pm 4.0$ & $2.23( \pm 3.17)$ & $3.48( \pm 4.72)$ & $\begin{array}{l}1.25 \\
(-0.51 ; 3.01)\end{array}$ & 0.3559 \\
\hline Nasal congestion & $3.9 \pm 3.9$ & $3.33( \pm 4.05)$ & $4.53( \pm 3.64)$ & $\begin{array}{l}1.20 \\
(-0.49 ; 2.89)\end{array}$ & 0.3559 \\
\hline Dyspnea & $3.5 \pm 4.5$ & $1.28( \pm 1.63)$ & $5.70( \pm 5.31)$ & $\begin{array}{l}4.43 \\
(2.70 ; 6.15)\end{array}$ & $<0.0001 *$ \\
\hline Muscle Fatigue & $8.5 \pm 5.3$ & $6.40( \pm 4.82)$ & $10.58( \pm 4.96)$ & $\begin{array}{l}4.18 \\
(2.03 ; 6.32)\end{array}$ & 0.0019* \\
\hline C-m.n-1 nn-1-1-. & $n \cap,[n$ & $=101,1,131$ & 1רז & 5.98 & \\
\hline
\end{tabular}




\section{Table 1}

Demographic, clinical characteristics of patients and symptoms outcome. Effect measures reported are mean differences and odds ratios for quantitate and qualitative variables correspondingly.

\begin{tabular}{|c|c|c|c|c|c|}
\hline & $\begin{array}{l}\text { Overall } \\
\text { patients } \\
(\mathrm{n}=80)\end{array}$ & $\begin{array}{l}\text { I+SOCG Intervention } \\
\text { Group } \\
(n=40)\end{array}$ & $\begin{array}{l}\text { SOCG Control } \\
\text { Group } \\
(n=40)\end{array}$ & $\begin{array}{l}\text { OR ( } 95 \% \text { Confidence } \\
\text { Interval) }\end{array}$ & $\begin{array}{l}\text { P- } \\
\text { Value }\end{array}$ \\
\hline $\begin{array}{l}\text { Angiotensin-converting enzyme (ACE) } \\
\text { inhibitors }\end{array}$ & $11(13.75)$ & $6(15.0 \%)$ & $5(12.5 \%)$ & $\begin{array}{l}1.23 \\
(0.33 ; 4.77)\end{array}$ & 1.0000 \\
\hline Angiotensin II receptor blockers & $6(7.5 \%)$ & $2(5.0 \%)$ & $4(10.0 \%)$ & $\begin{array}{l}0.37 \\
(0.11 ; 2.64)\end{array}$ & 0.6712 \\
\hline Beta blockers & $5(6.3 \%)$ & $5(12.5 \%)$ & $0(0.0 \%)$ & $\begin{array}{l}5,56 \\
(0.67 ; 235)\end{array}$ & 0.0647 \\
\hline Salbutamol & $5(6.3 \%)$ & $1(2.5 \%)$ & $4(10.0 \%)$ & $\begin{array}{l}0.18 \\
(0.05 ; 2.06)\end{array}$ & 0,3556 \\
\hline Benzodiazepines & $0(0.0 \%)$ & $0(0.0 \%)$ & $0(0.0 \%)$ & ---- & --- \\
\hline Antidepressants & $1(1.25 \%)$ & $0(0.0 \%)$ & $1(2.5 \%)$ & $\begin{array}{l}0 \\
(0.01 ; 8.22)\end{array}$ & 1.0000 \\
\hline Azithromycin & $0(0.0 \%)$ & $0(0.0 \%)$ & $0(0.0 \%)$ & ---- & ---- \\
\hline Ivermectin & $0(0.0 \%)$ & $0(0.0 \%)$ & $0(0.0 \%)$ & ---- & ---- \\
\hline Colchicine & $0(0.0 \%)$ & $0(0.0 \%)$ & $0(0.0 \%)$ & ---- & ---- \\
\hline Hydroxychloroquine & $0(0.0 \%)$ & $0(0.0 \%)$ & $0(0.0 \%)$ & --- & ---- \\
\hline Unfractionated heparin & $0(0.0 \%)$ & $0(0.0 \%)$ & $0(0.0 \%)$ & ----- & ---- \\
\hline Enoxaparin & $2(2.5 \%)$ & $1(2.5 \%)$ & $1(2.5 \%)$ & $\begin{array}{l}0.49 \\
(0.10 ; 10.03)\end{array}$ & 1.0000 \\
\hline Statins & $4(5.0 \%)$ & $4(10.0 \%)$ & $0(0.0 \%)$ & $\begin{array}{l}4.32 \\
(0.52 ; 192)\end{array}$ & 0.1238 \\
\hline Interferon & $0(0.0 \%)$ & $0(0.0 \%)$ & $0(0.0 \%)$ & ---- & ---- \\
\hline Glucocorticoids & $2(2.5 \%)$ & $1(2.5 \%)$ & $1(2.5 \%)$ & $\begin{array}{l}0.49 \\
(0.01 ; 10.03)\end{array}$ & 1.0000 \\
\hline NSAIDs & $1(1.3 \%)$ & $0(0.0 \%)$ & $1(2.5 \%)$ & $\begin{array}{l}0 \\
(0.01 ; 8.22)\end{array}$ & 1.0000 \\
\hline Opiates & $5(6.3 \%)$ & $5(15.5 \%)$ & $0(0.0 \%)$ & $\begin{array}{l}5.56 \\
(0.67 ; 235)\end{array}$ & 0.0646 \\
\hline Levothyroxine & $5(6.3 \%)$ & $2(5.0 \%)$ & $3(7.5 \%)$ & $\begin{array}{l}0.47 \\
(0.13 / 3.75)\end{array}$ & 1.0000 \\
\hline
\end{tabular}

\section{Table 2}

Non-SOC medications related to existing comorbidities previous to SARS-CoV-2 infection. 
Number of days with discomfort (Mean and SD) over 14 days of CAM nasal administration

\begin{tabular}{l|l}
\hline Nasal Itching & $8.50( \pm 4.20)$ \\
\hline Oropharyngeal discomfort & $6.30( \pm 4.30)$ \\
\hline Dizziness & $0.80( \pm 1.39)$ \\
\hline Nausea & $1.43( \pm 2.14)$ \\
\hline Headache & $3.05( \pm 2.91)$ \\
\hline Slight increase in heart rate & $0.40( \pm 1.33)$ \\
\hline Hypotension & $0.20( \pm 0.90)$ \\
\hline Lacrimation & $7.02( \pm 5.39)$ \\
\hline General Malaise & $2.77( \pm 3.71)$
\end{tabular}

\section{Table 3}

Discomfort after Cholinergic Agent Mixture (CAM) in nasal spray delivery administration in the intervention group (I+SOCG). No discomforts were observed in the oral drop ingestion of CAM. Average for each discomfort in number of days on 14 days. The aggregated duration of discomfort in minutes after application of CAM in nasal spray delivery for all symptoms was 7 minutes with an SD of 4 minutes.

\section{DISCUSSION}

This study is the first randomized trial evaluation of a specific combination of cholinergic nicotinic agents as adjuvant therapy in the treatment of out care symptomatic adult patients with confirmed COVID-19. Tolerance to the drug was good with no relevant nor long-lasting side effects. CAM drug showed to be a protective factor reducing significatively the number of days for cough, cephalea, dyspnea, muscle fatigue and general malaise.

According to previous published meta-analysis, the most prevalent COVID-19 symptoms in the severe COVID-19 disease group were cough (70.5\%), fever (64.1\%) and fatigue (44.5\%); in the ICU group these were cough (67.2\%), fever (62.9\%) and dyspnea (61.2\%) (77). The highest risk among comorbidities for ICU admission were hypertension and cardiovascular disease, both predictive for both severe disease and even more strongly associated to ICU admission (77). In our study we found that, although the intervention group had a significantly higher presence of cardiovascular disease $(p=0.0121)$, the evolution of symptoms was significantly positive when compared to control group. Interestingly, being cough and fatigue predictive signs for severe COVID-19 and cough and dyspnea for ICU admission (77), we found in our study that CAM seems to be a significant factor for remission and improvement of these three symptoms. If confirmed in larger studies, CAM could be a candidate of public health relevance in the remission of cough, fatigue and dyspnea, and its administration could have a beneficial impact on the reduction of these three predictor symptoms for severe disease or ICU admission.

Since dyspnea is the only predictive symptom with significance for hospitalization and admission to the ICU according to meta-analysis (77), we wish to highlight, following the results obtained in this study in the reduction of days in the intervention group, the importance of the beneficial effects of CAM on dyspnea 
symptom, being 1.28 days $( \pm 1.63)$ in the intervention group and 5.70 days $( \pm 5.31)$ in the control group (measure of effect $4.43[2.70 ; 6.15]$; adjusted p-value $<0.0001$ ).

CAM drug may be a valid candidate for further clinical research being of rapid development, low cost, easy storage, and exhibiting preliminary a good tolerance and safety in agreement with other drugs of the same category. CAM should be explored as a candidate for an over-the-counter product in the prevention or treatment of COVID-19 out care patients or also as an inward patient's hospital product under oral, nasal and/or nebulized administration.

Because Long-Covid is also an important Public Health issue (78-84) that could be probably described as the sequalae following the intoxication and disruption of the cholinergic system, cholinergic agonist combinations such as CAM should be further studied to elucidate if they can also be of use in the recovery of Long-Covid patients.

\section{CONCLUSION}

In an outpatient treatment setting, the novel combination of Cholinergic Agent Mixture (CAM) in nasal spray and oral drops led to statistically and clinically significant improvements at day 14 from randomization in a composite clinical endpoint. Importantly, CAM reduced the duration of dyspnea by 4.43 days (95\% Cl: $2.70 ; 6.15, \mathrm{p}<0.0001)$, as well as four other symptoms including cough, general malaise, muscle fatigue and cephalea. These findings are encouraging because dyspnea, cough, and fatigue are highly prevalent and strongly linked with severe disease, hospitalization and death. Larger randomized studies are needed to confirm our results and to further evaluate the public health implications of CAM.

\section{LIMITATIONS OF THE STUDY}

Sample size: The study results are limited to the number of patients included in it, 80 (40 for intervention group and 40 for control group). This has been a randomized open-label trial pilot study. It is suggested that the same study be conducted with larger multicenter studies that include higher number of patients in both groups with double blind randomized trials with placebo group.

\section{AUTHOR'S STATEMENTS}

The authors hereby declare:

- The authors of this study do not promote the use of the smoked cigarette on the contrary, they advise against it under any circumstances, and they are not promoting or encouraging the use of alternative products such as electronic cigarettes for harm-reduction or smoking cessation products as NRT's for fighting COVID-19. This is another discussion.

- It is of interest to the authors to point out that although the smoked cigarette and its added components and smoked route of administration are clearly harmful, the tobacco plant and cholinergic agonist molecules are of therapeutic interest in the COVID-19 disease if they are treated and explored in a scientific and medicinal way, leaving aside controversies and stigmatizations that may well apply to the industry and the consumption of cigarettes, but should not be mixed with the therapeutic potential of medicinal drugs based on such molecules with a scientific pharmacological design and from a pure 
medical perspective for the benefit of human health.

\section{FUNDING STAMEMENT}

This study did not receive any specific grant from funding agencies in the public, commercial, or not-forprofit sectors. The authors have not obtained any funding from the tobacco industry, nor from the vaping industry nor NRT-related products companies.

\section{CREDIT AUTHORSHIP CONTRIBUTION STATEMENT}

León Higuera J.G.: Methodology, Investigation, Conceptualization, Supervision; Restrepo Guerrero F.H: Software, statistical analysis; León García M.: review \& supervision; Politi M.: review, supervision; Mendive F.: project advisor, review \& editing; Angulo Ceballos O.: Conceptualization, Supervision, Writing - original draft, Writing-, review \& editing.

\section{DECLARATION OF COMPETING INTEREST}

The authors report no declarations of interest. Two international (PCT) patent applications have been filed relating to the formulation of CAM. But none of the authors are applicants or related to them.

\section{ACKNOWLEDGEMENTS}

Not applicable

\section{COPYRIGHT}

All images and graphics in this article are of own development and property of the authors. No external images have been used involving third party copyrights.

\section{REFERENCES}

1. Changeux J-P, Amoura Z, Rey FA, Miyara M. A nicotinic hypothesis for Covid-19 with preventive and therapeutic implications. Comptes Rendus Biol [Internet]. 2020 Jun 5;343(1):33-9. Available from: https://comptes-rendus.academie-sciences.fr/biologies/item/CRBIOL_2020_343_1_33_0

2. Farsalinos K, Barbouni A, Niaura R. Systematic review of the prevalence of current smoking among hospitalized COVID-19 patients in China: could nicotine be a therapeutic option? Intern Emerg Med [Internet]. 2020 Aug 9;15(5):845-52. Available from: http://link.springer.com/10.1007/s11739-020-02355-7

3. Mo P, Xing Y, Xiao Y, Deng L, Zhao Q, Wang H, et al. Clinical characteristics of refractory COVID-19 pneumonia in Wuhan, China. Clin Infect Dis [Internet]. 2020 Mar 16; Available from: https://academic.oup.com/cid/advance-article/doi/10.1093/cid/ciaa270/5805508

4. Farsalinos K, Barbouni A, Poulas K, Polosa R, Caponnetto P, Niaura R. Current smoking, former smoking, and adverse outcome among hospitalized COVID-19 patients: a systematic review and metaanalysis. Ther Adv Chronic Dis [Internet]. 2020 Jan 25;11:204062232093576. Available from: http://journals.sagepub.com/doi/10.1177/2040622320935765

5. Farsalinos K, Bagos PG, Giannouchos T, Niaura R, Barbouni A, Poulas K. Smoking prevalence among hospitalized COVID-19 patients and its association with disease severity and mortality: an expanded reanalysis of a recent publication. Harm Reduct J. 2021;18(1).

6. Farsalinos K, Niaura R, Le Houezec J, Barbouni A, Tsatsakis A, Kouretas D, et al. Editorial: Nicotine 
and SARS-CoV-2: COVID-19 may be a disease of the nicotinic cholinergic system. Toxicol Reports [Internet]. 2020;7:658-63. Available from: https://linkinghub.elsevier.com/retrieve/pii/S2214750020302924 7. Gonzalez-Rubio J, Navarro-Lopez C, Lopez-Najera E, Lopez-Najera A, Jimenez-Diaz L, Navarro-Lopez JD, et al. Cytokine Release Syndrome (CRS) and Nicotine in COVID-19 Patients: Trying to Calm the Storm. Front Immunol [Internet]. 2020 Jun 11;11. Available from: https://www.frontiersin.org/article/10.3389/fimmu.2020.01359/full

8. Fu L, Wang B, Yuan T, Chen X, Ao Y, Fitzpatrick T, et al. Clinical characteristics of coronavirus disease 2019 (COVID-19) in China: A systematic review and meta-analysis. J Infect [Internet]. 2020 Jun;80(6):65665. Available from: https://linkinghub.elsevier.com/retrieve/pii/S0163445320301705

9. Petrilli CM, Jones SA, Yang J, Rajagopalan H, O'Donnell L, Chernyak Y, et al. Factors associated with hospital admission and critical illness among 5279 people with coronavirus disease 2019 in New York City: prospective cohort study. BM] [Internet]. 2020 May 22;m1966. Available from: https://www.bmj.com/lookup/doi/10.1136/bmj.m1966

10. Chow N, Fleming-Dutra K, Gierke R, Hall A, Hughes M, Pilishvili T, et al. Preliminary Estimates of the Prevalence of Selected Underlying Health Conditions Among Patients with Coronavirus Disease 2019 United States, February 12-March 28, 2020. MMWR Morb Mortal Wkly Rep [Internet]. 2020 Apr 3;69(13):382-6. Available from: http://www.cdc.gov/mmwr/volumes/69/wr/mm6913e2.htm? s_cid $=$ mm6913e2_w

11. González-Rubio J, Navarro-López C, López-Nájera E, López-Nájera A, Jiménez-Díaz L, Navarro-López JD, et al. A Systematic Review and Meta-Analysis of Hospitalised Current Smokers and COVID-19. Int J Environ Res Public Health [Internet]. 2020 Oct 11;17(20):7394. Available from:

https://www.mdpi.com/1660-4601/17/20/7394

12. van Westen-Lagerweij NA, Meijer E, Meeuwsen EG, Chavannes NH, Willemsen MC, Croes EA. Are smokers protected against SARS-CoV-2 infection (COVID-19)? The origins of the myth. npj Prim Care Respir Med. 2021;31(1).

13. Saraiya T, Farsalinos K, Poulas K, Labrou D. Implications of the SARS-CoV-2 spike protein interaction with type-1 macrophages via $\alpha 7-n A C h R$. Qeios [Internet]. 2021 Mar 16; Available from: https://www.qeios.com/read/26GTOD

14. Lagoumintzis G, Chasapis CT, Alexandris N, Kouretas D, Tzartos S, Eliopoulos E, et al. Nicotinic cholinergic system and COVID-19: In silico identification of interactions between $\alpha 7$ nicotinic acetylcholine receptor and the cryptic epitopes of SARS-Co-V and SARS-CoV-2 Spike glycoproteins. Food Chem Toxicol. $2021 ; 149$.

15. Yuan M, Wu NC, Zhu X, Lee CCD, So RTY, Lv H, et al. A highly conserved cryptic epitope in the receptor binding domains of SARS-CoV-2 and SARS-CoV. Science (80- ). 2020;368(6491):630-3.

16. Farsalinos K, Eliopoulos E, Leonidas DD, Papadopoulos GE, Tzartos S, Poulas K. Nicotinic Cholinergic System and COVID-19: In Silico Identification of an Interaction between SARS-CoV-2 and Nicotinic Receptors with Potential Therapeutic Targeting Implications. Int J Mol Sci [Internet]. 2020 Aug 
13;21(16):5807. Available from: https://www.mdpi.com/1422-0067/21/16/5807

17. Cheng MH, Zhang S, Porritt RA, Rivas MN, Paschold L, Willscher E, et al. Superantigenic character of an insert unique to SARS-CoV-2 spike supported by skewed TCR repertoire in patients with hyperinflammation. Proc Natl Acad Sci U S A. 2020;117(41):25254-62.

18. Pavlov VA, Wang H, Czura CJ, Friedman SG, Tracey KJ. The Cholinergic Anti-inflammatory Pathway: A Missing Link in Neuroimmunomodulation. Mol Med. 2003;9(5-8):125-34.

19. Alexandris N, Lagoumintzis G, Chasapis CT, Leonidas DD, Papadopoulos GE, Tzartos SJ, et al. Nicotinic cholinergic system and COVID-19: In silico evaluation of nicotinic acetylcholine receptor agonists as potential therapeutic interventions. Toxicol Reports [Internet]. 2021;8:73-83. Available from: https://linkinghub.elsevier.com/retrieve/pii/S2214750020304583

20. Lemprière S. Single-cell transcriptomics reveals neuroinflammation in severe COVID-19. Nat Rev Neurol. 2021;17(8):461.

21. Tomasoni D, Bai F, Castoldi R, Barbanotti D, Falcinella C, Mulè G, et al. Anxiety and depression symptoms after virological clearance of COVID-19: A cross-sectional study in Milan, Italy. J Med Virol. 2021;93(2):1175-9.

22. Daroische R, Hemminghyth MS, Eilertsen TH, Breitve MH, Chwiszczuk LJ. Cognitive Impairment After COVID-19-A Review on Objective Test Data. Front Neurol. 2021;12.

23. Mastropaolo J, Rosse RB, Deutsch SI. Anabasine, a selective nicotinic acetylcholine receptor agonist, antagonizes MK-801-elicited mouse popping behavior, an animal model of schizophrenia. Behav Brain Res. 2004;153(2):419-22.

24. Nemani K, Li C, Olfson M, Blessing EM, Razavian N, Chen J, et al. Association of Psychiatric Disorders with Mortality among Patients with COVID-19. JAMA Psychiatry. 2021;78(4):380-6.

25. Villafane G, Thiriez C, Audureau E, Straczek C, Kerschen P, Cormier-Dequaire F, et al. High-dose transdermal nicotine in Parkinson's disease patients: a randomized, open-label, blinded-endpoint evaluation phase 2 study. Eur J Neurol [Internet]. 2018 Jan;25(1):120-7. Available from: http://doi.wiley.com/10.1111/ene.13474

26. Newhouse P, Kellar K, Aisen P, White H, Wesnes K, Coderre E, et al. Nicotine treatment of mild cognitive impairment: A 6-month double-blind pilot clinical trial. Neurology [Internet]. 2012 Jan 10;78(2):91-101. Available from: http://www.neurology.org/cgi/doi/10.1212/WNL.0b013e31823efcbb 27. Schnoll RA, Goelz PM, Veluz-Wilkins A, Blazekovic S, Powers L, Leone FT, et al. Long-term Nicotine Replacement Therapy. JAMA Intern Med [Internet]. 2015 Apr 1;175(4):504. Available from: http://archinte.jamanetwork.com/article.aspx?doi=10.1001/jamainternmed.2014.8313 28. California $U$ of. Pharmacologic product guide: FDA-Approved Medications for Smoking Cessation [Internet]. 2019. p. 2. Available from:

https://www.aafp.org/dam/AAFP/documents/patient_care/tobacco/pharmacologic-guide.pdf 29. Oncken C, Campbell W, Chan G, Hatsukami D, Kranzler HR. Effects of nicotine patch or nasal spray on nicotine and cotinine concentrations in pregnant smokers. J Matern Neonatal Med. 2009;22(9):751-8. 
30. Villafane G, Cesaro P, Rialland A, Baloul S, Azimi S, Bourdet C, et al. Chronic high dose transdermal nicotine in Parkinson's disease: An open trial. Eur J Neurol. 2007;14(12):1313-6.

31. Benowitz NL, Hansson A, Jacob P. Cardiovascular Effects of Nasal and Transdermal Nicotine and Cigarette Smoking. Hypertension [Internet]. 2002 Jun;39(6):1107-12. Available from:

https://www.ahajournals.org/doi/10.1161/01.HYP.0000018825.76673.EA

32. Kimmel SE, Berlin JA, Miles C, Jaskowiak J, Carson JL, Strom BL. Risk of acute first myocardial infarction and use of nicotine patches in a general population. J Am Coll Cardiol [Internet]. 2001 Apr;37(5):1297-302. Available from: https://linkinghub.elsevier.com/retrieve/pii/S073510970101124X 33. Joseph AM, Norman SM, Ferry LH, Prochazka A V., Westman EC, Steele BG, et al. The Safety of Transdermal Nicotine as an Aid to Smoking Cessation in Patients with Cardiac Disease. N Engl J Med [Internet]. 1996 Dec 12;335(24):1792-8. Available from: http://www.nejm.org/doi/abs/10.1056/NEJM199612123352402

34. Ware JH, Vetrovec GW, Miller AB, Van Tosh A, Gaffney M, Yunis C, et al. Cardiovascular Safety of Varenicline. Am J Ther [Internet]. 2013 Apr;1. Available from: http://journals.Iww.com/00045391900000000-99413

35. Woolf KJ, Zabad MN, Post JM, McNitt S, Williams GC, Bisognano JD. Effect of nicotine replacement therapy on cardiovascular outcomes after acute coronary syndromes. Am J Cardiol. 2012;110(7):968-70. 36. Benowitz NL, Gourlay SG. Cardiovascular Toxicity of Nicotine: Implications for Nicotine Replacement Therapy 11All editorial decisions for this article, including selection of referees, were made by a Guest Editor. This policy applies to all articles with authors from the Universi. J Am Coll Cardiol [Internet]. 1997 Jun;29(7):1422-31. Available from: https://linkinghub.elsevier.com/retrieve/pii/S073510979700079X 37. Zevin S, Jacob P, Benowitz NL. Dose-related cardiovascular and endocrine effects of transdermal nicotine*. Clin Pharmacol Ther [Internet]. 1998 Jul;64(1):87-95. Available from: http://doi.wiley.com/10.1016/S0009-9236(98)90026-1

38. Apelberg BJ, Onicescu G, Avila-Tang E, Samet JM. Estimating the Risks and Benefits of Nicotine Replacement Therapy for Smoking Cessation in the United States. Am J Public Health [Internet]. 2010 Feb;100(2):341-8. Available from: http://ajph.aphapublications.org/doi/10.2105/AJPH.2008.147223 39. Hecht SS. Tobacco carcinogens, their biomarkers and tobacco-induced cancer. Nat Rev Cancer [Internet]. 2003 Dec;3(10):733-44. Available from: http://www.nature.com/articles/nrc1190 40. Fishbein L, O'Brien P, Hutson A, Theriaque D, Stacpoole PW, Flotte T. Pharmacokinetics and pharmacodynamic effects of nicotine nasal spray devices on cardiovascular and pulmonary function. J Investig Med. 2000;48(6):435-40.

41. Hatsukami DK, Grillo M, Pentel PR, Oncken C, Bliss R. Safety of cotinine in humans: Physiologic, subjective, and cognitive effects. Pharmacol Biochem Behav. 1997;57(4):643-50.

42. Echeverria V, Alex Grizzell J, E. Barreto G. Neuroinflammation: A Therapeutic Target of Cotinine for the Treatment of Psychiatric Disorders? Curr Pharm Des. 2016;22(10):1324-33.

43. Levin ED, Hao I, Burke DA, Cauley M, Hall BJ, Rezvani AH. Effects of tobacco smoke constituents, 
anabasine and anatabine, on memory and attention in female rats. J Psychopharmacol. 2014;28(10):91522.

44. Caine SB, Collins GT, Thomsen M, Wright C, Lanier RK, Mello NK. Nicotine-like behavioral effects of the minor tobacco alkaloids nornicotine, anabasine, and anatabine in male rodents. Exp Clin Psychopharmacol. 2014;22(1):9-22.

45. Mello NK, Fivel PA, Kohut SJ, Caine SB. Anatabine significantly decreases nicotine selfadministration. Exp Clin Psychopharmacol. 2014;22(1):1-8.

46. D. P, D. B-A, L. A, C. B, G. A-G, J. R, et al. Anti-inflammatory activity of anatabine via inhibition of STAT3 phosphorylation. Eur J Pharmacol. 2013;698(1-3):145-53.

47. Del Valle DM, Kim-Schulze S, Huang HH, Beckmann ND, Nirenberg S, Wang B, et al. An inflammatory cytokine signature predicts COVID-19 severity and survival. Nat Med. 2020;26(10):1636-43.

48. Suekawa M, Ishige A, Yuasa K, Sudo K, Aburada M, Hosoya E. Pharmacological studies on ginger. I. Pharmacological actions of pungent constituents, (6)-gingerol and (6) -shogaol. J Pharmacobiodyn. 1984;7(11):836-48.

49. Kim EC, Min JK, Kim TY, Lee S], Yang HO, Han S, et al. [6]-Gingerol, a pungent ingredient of ginger, inhibits angiogenesis in vitro and in vivo. Biochem Biophys Res Commun. 2005;335(2):300-8.

50. Chan L, Gyu HP, Chang-Yul K, Jung-Hee J. [6]-Gingerol attenuates $\beta$-amyloid-induced oxidative cell death via fortifying cellular antioxidant defense system. Food Chem Toxicol. 2011;49(6):1261-9.

51. Son MJ, Miura Y, Yagasaki K. Mechanisms for antidiabetic effect of gingerol in cultured cells and obese diabetic model mice. Cytotechnology. 2015;67(4):641-52.

52. El-Bassossy HM, Elberry AA, Ghareib SA, Azhar A, Banjar ZM, Watson ML. Cardioprotection by 6gingerol in diabetic rats. Biochem Biophys Res Commun. 2016;477(4):908-14.

53. Means C. Mechanisms of increased morbidity and mortality of SARS-CoV-2 infection in individuals with diabetes: what this means for an effective management strategy. Metabolism. 2020;108.

54. Kim KM, Chun SB, Koo MS, Choi WJ, Kim TW, Kwon YG, et al. Differential regulation of NO availability from macrophages and endothelial cells by the garlic component S-allyl cysteine. Free Radic Biol Med. 2001;30(7):747-56.

55. Amagase H. Clarifying the real bioactive constituents of garlic. J Nutr. 2006;136(3).

56. Rojas P, Serrano-García N, Medina-Campos ON, Pedraza-Chaverri J, Maldonado PD, Ruiz-Sánchez E. S-Allylcysteine, a garlic compound, protects against oxidative stress in 1-methyl-4-phenylpyridiniuminduced parkinsonism in mice. J Nutr Biochem. 2011;22(10):937-44.

57. Pandey P, Khan F, Kumar A, Srivastava A, Jha NK. Screening of potent inhibitors against 2019 novel coronavirus (Covid-19) from alliumsativum and allium cepa: An in silico approach. Biointerface Res Appl Chem. 2021;11(1):7981-93.

58. SCHNEIDER NG, OLMSTEAD R, MODY FV, DOAN K, FRANZON M, JARVIK ME, et al. Efficacy of a nicotine nasal spray in smoking cessation: a placebo-controlled, double-blind trial. Addiction. 1995;90(12):1671-82. 
59. Sutherland G, Stapleton JA, Russell MAH, Jarvis MJ, Hajek P, Belcher M, et al. Randomised controlled trial of nasal nicotine spray in smoking cessation. Lancet. 1992;340(8815):324-9.

60. Olsson P, Kuylenstierna F, Johansson C-J, Gunnarsson P, Bende M. Pharmacokinetics of Nicotine after Intranasal Administration. Eff Nicotine Biol Syst. 1991;57-61.

61. Benowitz NL, Hukkanen J, Jacob P. Nicotine Chemistry, Metabolism, Kinetics and Biomarkers. In 2009. p. 29-60. Available from: http://link.springer.com/10.1007/978-3-540-69248-5_2

62. Russell MAH, Jarvis MJ, Feyerabend C, Ferno O. Nasal nicotine solution: A potential aid to giving up smoking? Br Med J. 1983;286(6366):683-4.

63. Munari AB, Gulart AA, Dos Santos K, Venâncio RS, Karloh M, Mayer AF. Modified Medical Research Council Dyspnea Scale in GOLD Classification Better Reflects Physical Activities of Daily Living. Respir Care. 2018;63(1):77-85.

64. Cabral LL, Lopes PB, Wolf R, Stefanello JMF, Pereira G. A systematic review of cross-cultural adaptation and validation of Borg's Rating Of Perceived Exertion Scale. J Phys Educ. 2017;28(1).

65. Maher LLM. The Borg Rating of Perceived Exertion (RPE) Scale. Care Obese Adv Pract Nurs. 2018;

66. Kildesø J, Wyon D, Skov T, Schneider T. Visual analogue scales for detecting changes in symptoms of the sick building syndrome in an intervention study. Scand J Work Environ Heal. 1999;25(4):361-7.

67. Micklewright D, St Clair Gibson A, Gladwell V, Al Salman A. Development and Validity of the Ratingof-Fatigue Scale. Sport Med. 2017;47(11):2375-93.

68. Santus P, Tursi F, Croce G, Simone C Di, Frassanito F, Gaboardi P, et al. Changes in quality of life and dyspnoea after hospitalization in COVID-19 patients discharged at home. Multidiscip Respir Med. 2020;15. 69. Wu Q, Hou X, Li H, Guo J, Li Y, Yang F, et al. A follow-up study of respiratory and physical function after discharge in patients with redetectable positive SARS-CoV-2 nucleic acid results following recovery from COVID-19. Int J Infect Dis. 2021;107:5-11.

70. Ramalho SHR, Santos M, Claggett B, Matsushita K, Kitzman DW, Loehr L, et al. Association of Undifferentiated Dyspnea in Late Life With Cardiovascular and Noncardiovascular Dysfunction. JAMA Netw Open. 2019;2(6):e195321.

71. Stephenson JJ, Wertz D, Gu T, Patel J, Dalal AA. Clinical and economic burden of dyspnea and other COPD symptoms in a managed care setting. Int J COPD. 2017;12:1947-59.

72. Small M, Holbrook T, Wood R, Mullerova H, Naya I, Punekar YS. Prevalence and burden of dyspnoea among COPD patients in Japan. Int J Clin Pract. 2016;70(8):676-81.

73. Shinya Yamauchi SM. Rating of Perceived Exertion for Quantification of the Intensity of Resistance Exercise. Int J Phys Med Rehabil. 2013;01(09).

74. Rasch D, Teuscher F, Guiard V. How robust are tests for two independent samples? J Stat Plan Inference. 2007;137(8):2706-20.

75. Y. B, D. Y. The control of the false discovery rate in multiple testing under dependency. Ann Stat. 2001;29(4):1165-88.

76. Dexter TA. R: a language and environment for statistical computing. Quat Res. 2014;81(2):114-24. 
77. Jain V, Yuan JM. Predictive symptoms and comorbidities for severe COVID-19 and intensive care unit admission: a systematic review and meta-analysis. Int J Public Health. 2020;65(5):533-46.

78. Carfì A, Bernabei R, Landi F. Persistent Symptoms in Patients After Acute COVID-19. JAMA [Internet]. 2020 Aug 11;324(6):603. Available from: https://jamanetwork.com/journals/jama/fullarticle/2768351

79. Zhao Y, Shang Y, Song W, Li Q, Xie H, Xu Q, et al. Follow-up study of the pulmonary function and related physiological characteristics of COVID-19 survivors three months after recovery. EClinicalMedicine [Internet]. 2020 Aug;25:100463. Available from:

https://linkinghub.elsevier.com/retrieve/pii/S2589537020302078

80. Galván-Tejada CE, Herrera-García CF, Godina-González S, Villagrana-Bañuelos KE, Amaro JDDL, Herrera-García K, et al. Persistence of COVID-19 Symptoms after Recovery in Mexican Population. Int J Environ Res Public Health [Internet]. 2020 Dec 14;17(24):9367. Available from:

https://www.mdpi.com/1660-4601/17/24/9367

81. Townsend L, Dyer AH, Jones K, Dunne J, Mooney A, Gaffney F, et al. Persistent fatigue following SARS-CoV-2 infection is common and independent of severity of initial infection. PLoS One. 2020;15(11 November).

82. Miller A. COVID -19: not just an acute illness. Trends Urol Men's Heal [Internet]. 2020 Nov 26;11(6):17-9. Available from: https://onlinelibrary.wiley.com/doi/10.1002/tre.776

83. Goërtz YMJ, Van Herck M, Delbressine JM, Vaes AW, Meys R, Machado FVC, et al. Persistent symptoms 3 months after a SARS-CoV-2 infection: the post-COVID-19 syndrome? ERJ Open Res [Internet]. 2020 Oct;6(4):00542-2020. Available from:

http://openres.ersjournals.com/lookup/doi/10.1183/23120541.00542-2020

84. Tenforde MW, Kim SS LC et al. Symptom Duration and Risk Factors for Delayed Return to Usual Health Among Outpatients with COVID-19 in a Multistate Health Care Systems Network - United States, March-June 2020 [Internet]. Available from: https://www.cdc.gov/mmwr/volumes/69/wr/mm6930e1.htm 